\title{
7.4 \\ La Financiación especial de las Pymes
}

D. Juan Antonio González Royuela

Director de Banca de Pymes de B.B.K.

Egun on guztioi / Buenos días a todos:

Quiero agradecer en nombre de BBK la oportunidad que nos ha brindado el Instituto de Estudios Vascos de la Universidad de Deusto y la AIDC, para compartir con Vds. estas JORNADAS PRACTICAS SOBRE LA FINANCIACION DE LAS EMPRESAS.

Aunque a estas alturas de la Jornada estarán Vds. un poco cansados, recojo el testigo para esta cuarta y última Ponencia con la intención de transmitirles una visión amena que mantenga su interés y, por supuesto, les ayude a situar adecuadamente la problemática derivada de la financiación de las empresas PYMES.

Es muy probable que durante mi exposición incurra en redundancias con alguno de mis predecesores (espero que no sean contradicciones) pero, en cualquier caso, trataré de enriquecer nuestra capacidad de análisis y asesoramiento, objetivo que, seguro, vamos a conseguir.

\section{Las pequeñas y medianas empresas en Bizkaia}

Entrando en materia, mi exposición va a versar sobre la financiación de las empresas PYMES. Así pues, lo primero será encuadrar a qué nos estamos refiriendo cuando distinguimos PYMES dentro del colectivo general.

A la hora de concretar este concepto, según el referente utilizado, nos encontramos con distintos parámetros, hay diferentes apreciaciones. 
No obstante, los criterios sustantivos son casi coincidentes $v$ los podemos ver resumidos en el siguiente cuadro (Figura 1).

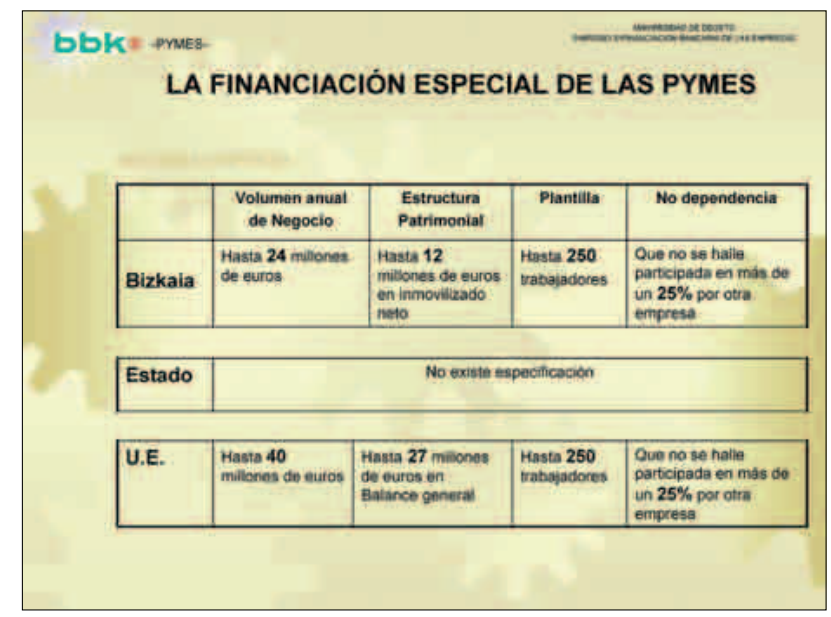

Figura 1

Como pueden observar, tanto en Bizkaia como a nivel europeo, una empresa para ser clasificada como PYME no debe rebasar los siguientes límites:

- Ser empresas que no superen los 250 trabajadores.

- Que no se hallen participadas en más de un $25 \%$ por otras empresas.

— Su volumen de negocio no debe exceder de 24 millones de $€$ y

- Su estructura patrimonial no ser superior a los 12 millones de $€$ de Inmovilizado neto.

A nivel del Estado, no existe definición concreta de empresa PYME.

Dentro de las PYMES existe a su vez, una subdivisión en cuanto a lo que se determina como pequeña empresa (Figura 2), que abarcaría aquellas empresas que no superen los 50 trabajadores y cuyo volumen de negocio se sitúe por debajo de los 6 millones de $€$ anuales, con una estructura patrimonial / inmovilizado neto de hasta 2,4 millones.

Una vez conocidos los parámetros para encuadrar el colectivo PYMES, se trata ahora de situar la importancia que este tipo de empresas supone en el contexto general de la actividad económica. 


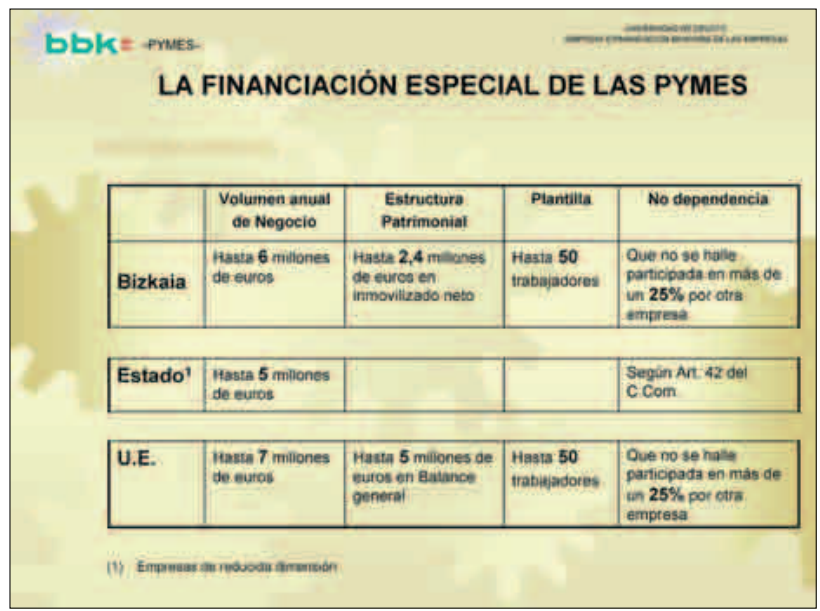

Figura 2

Para ello les comentaré unos datos estratificados de las empresas de Bizkaia (Figura 3).

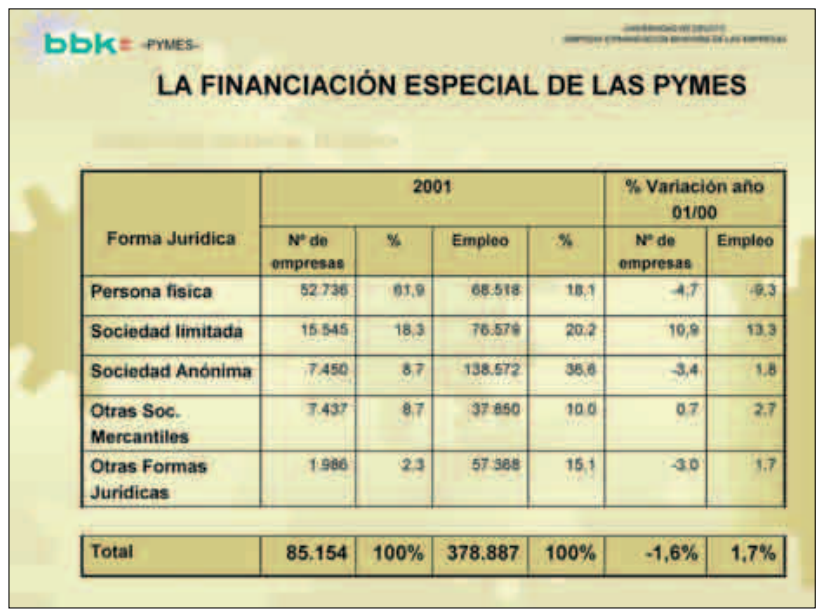

Figura 3

Según los datos que les estoy mostrando, correspondientes a la forma jurídica de las Estructuras Empresariales en Bizkaia, pueden observar cómo las sociedades anónimas (9\% del total) aportan el $37 \%$ 
del empleo. Otro $20 \%$ lo aportan las Sociedades Limitadas, que suponen el $18 \%$ de las empresas.

La tercera figura por orden de importancia (personas físicas), aglutina el $18 \%$ del empleo, y alcanza al $62 \%$ del número de empresas.

Primer dato, muy revelador, de la importancia de la pequeña y mediana empresa y su aportación al conjunto.

En el siguiente cuadro (Figura 4) ordenado por sector de actividad, pueden apreciar cómo las empresas dedicadas a LOS SERVICIOS en general, tanto profesionales y empresariales como de cualquier otra índole, aglutinan el $37 \%$ del empleo en nuestra provincia y el $30 \%$ en el número de empresas.

\begin{tabular}{|c|c|c|c|c|c|c|}
\hline \multicolumn{7}{|l|}{$\begin{array}{l}\text { bbk }=\text { pries } \\
\text { LA FI }\end{array}$} \\
\hline \multirow[b]{2}{*}{ Forma Juridica } & \multicolumn{4}{|c|}{2001} & \multicolumn{2}{|c|}{$\%$ Variación ano $01 / 00$} \\
\hline & $\begin{array}{c}N^{0} \text { de } \\
\text { empresas }\end{array}$ & $\%$ & Empleo & $\%$ & $\begin{array}{c}N^{*} \text { de } \\
\text { empresas }\end{array}$ & Empleo \\
\hline Comercio y Reparación & 24.433 & 28.7 & 62.996 & 18.6 & 3.1 & 0.7 \\
\hline $\begin{array}{l}\text { Servicios Prof: y } \\
\text { Empresariales }\end{array}$ & 13.457 & 15.8 & 31326 & 13.5 & 70 & 8.3 \\
\hline $\begin{array}{l}\text { Otras Actividades de } \\
\text { Servicio }\end{array}$ & 12206 & 14.5 & 95488 & 2.6 & 1.2 & 1.8 \\
\hline Construcción & 9.752 & 11.5 & 35.801 & 9.8 & 64 & 8.8 \\
\hline Hostoleria & 8.175 & 26 & 18.652 & 4.9 & .129 & -12.3 \\
\hline $\begin{array}{l}\text { Transporte y } \\
\text { Comunicaciones }\end{array}$ & 8.065 & 75 & 24.317 & 8,4 & 2.2 & 2.5 \\
\hline Industria & 6748 & 79 & 80538 & 23.4 & 6.5 & 0.2 \\
\hline $\begin{array}{l}\text { Intermediación } \\
\text { Financiera }\end{array}$ & 2318 & 27 & 11708 & 31 & -1.3 & -0.3 \\
\hline Total & 85.154 & $100 \%$ & 378.887 & $100 \%$ & $-1,6 \%$ & $1,7 \%$ \\
\hline
\end{tabular}

Figura 4

En segundo lugar del rango por actividad estaría la INDUSTRIA, alcanzando el $23 \%$ del empleo, contando tan sólo con un $8 \%$ del número de empresas.

El tercer lugar de entre los más destacados lo ocuparía el COMERCIO Y REPARACIONES, que da trabajo a un $17,7 \%$ de la población empleada y lo componen el $29 \%$ de número de empresas.

En la parte derecha del cuadro, en los datos referentes a la variación del año pasado con respecto al anterior, se refleja cómo también en trayectoria de crecimiento, es el Sector SERVICIOS el más dinámico, 
aumentando el $8,3 \%$, seguido de la CONSTRUCCION, gran protagonista de los últimos años, con un 6,8\%.

Por contra, HOSTELERIA es la actividad que registra un mayor retroceso, en torno al (-12\%).

Tras esta primera reflexión sobre la forma societaria y la actividad de las empresas, a continuación vamos a analizarlas en función del número de empleados, datos muy elocuentes en cuanto al peso específico de cada grupo en la aportación al tejido económico de nuestro territorio.

Como pueden observar (Figura 5), el $60 \%$ del empleo está generado por empresas con menos de 50 trabajadores, pero las de menos de 10 trabajadores suponen, a su vez, el $60 \%$ de este grupo.

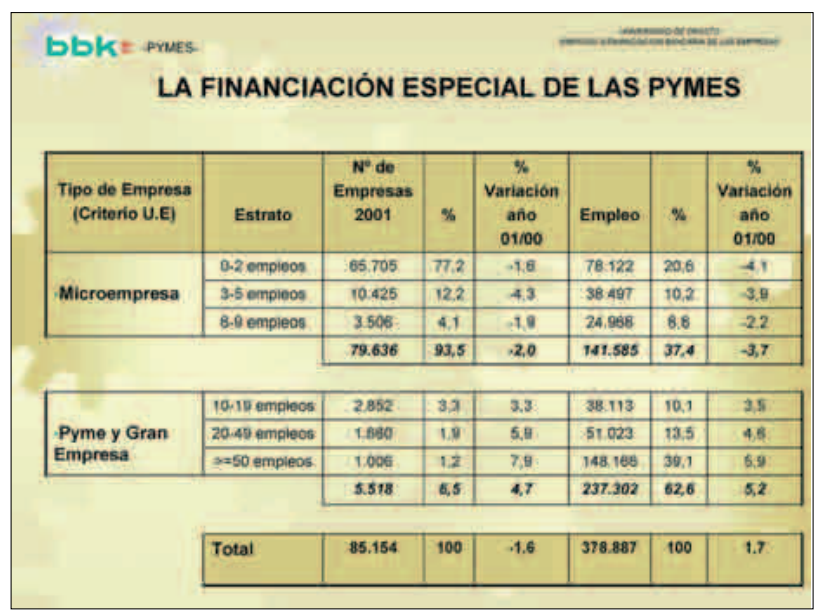

Figura 5

En función de la aportación de cada Sector al P.I.B., si comparamos los pesos específicos de 1980 con los del 2001, constataremos la terciarización que se ha producido (Figura 6).

Tanto en Bizkaia como en la Comunidad Autónoma, LOS SERVICIOS aportan más del $60 \%$ del Producto Interior Bruto, habiendo incrementado su peso específico más de 10 puntos en los últimos 20 años.

También la CONSTRUCCION recoge el fuerte auge experimentado, duplicando su importancia. 


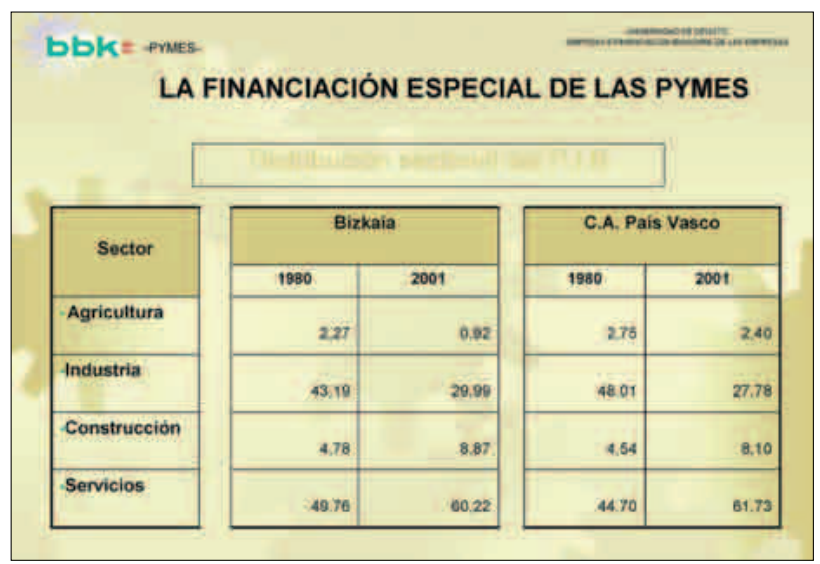

Figura 6

Por el contrario, es la INDUSTRIA quien sufre un fortísimo decremento, más de 13 puntos porcentuales.

La AGRICULTURA también sufre un retroceso, más acusado en BIZKAIA que en la Comunidad Autónoma.

Un último dato, importante, es el que surge de la comparación de nuestra estructura provincial con la del Estado y la de la Unión Europea (Figura 7).

\begin{tabular}{|c|c|c|c|}
\hline \multicolumn{3}{|c|}{ bbk= +mes. } & mansine \\
\hline \multicolumn{4}{|c|}{ LA FINANCIACIÓN ESPECIAL DE LAS PYMES } \\
\hline \multicolumn{4}{|c|}{ 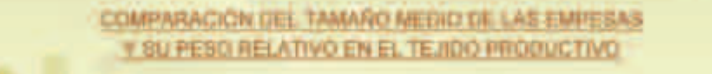 } \\
\hline \multicolumn{4}{|c|}{ Peso relativo de las empresas de menos de 50 trabajadores } \\
\hline Pais & $\begin{array}{c}\text { Plantilla } \\
\text { media }\end{array}$ & $\begin{array}{c}\mathrm{N}^{0} \text { de } \\
\text { empresas }\end{array}$ & Empleo \\
\hline UE - 15 & 5,9 & $99,-\%$ & $53,4 \%$ \\
\hline Estado & 4,7 & $99,3 \%$ & $66,8 \%$ \\
\hline Bizkaia & 4,3 & $98,9 \%$ & $62,4 \%$ \\
\hline
\end{tabular}

Figura 7 
Valores muy próximos en los tres niveles, resultando nuestra presencia la más atomizada de los tres.

A modo de resumen de esta primera parte, constatar la importancia del segmento PYMES. Los datos que acabamos de ver, explicitan el fuerte peso específico de este segmento para nuestra economía y de ahí el énfasis de la Administración en el cuidado y fomento de este sector, utilizando para ello una dotación muy importante de recursos.

\section{Instrumentos financieros especiales para las PYMES}

Los instrumentos financieros utilizados habitualmente, vamos a clasificarlos de acuerdo con la finalidad a la que tienen que atender (Figura 8):

- Para la obtención de Capitales.

- Para la financiación del Inmovilizado.

- Para la financiación de Capital circulante.

- Para el resto de servicios financieros.

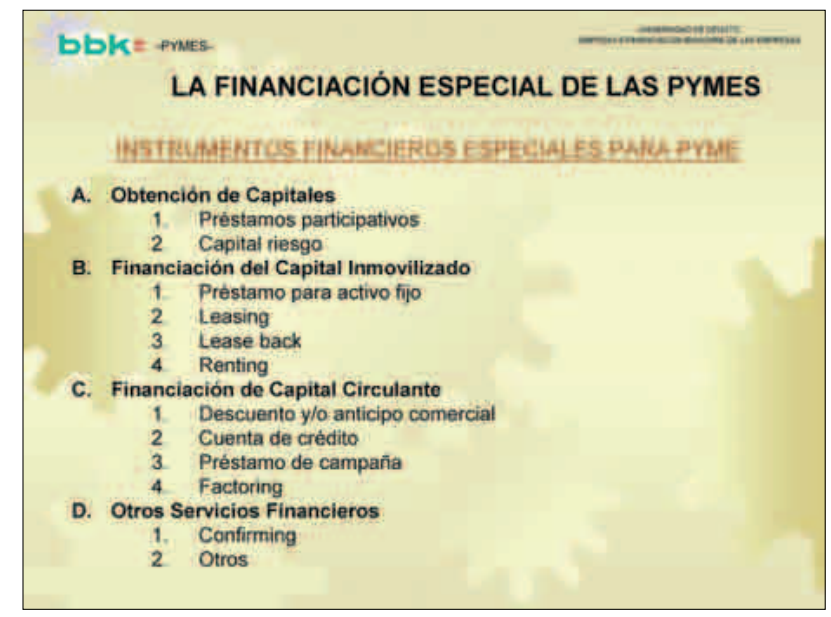

Figura 8

Comenzamos el proceso de análisis por las posibilidades existentes en cuanto a la financiación de Capital (Figura 9). 


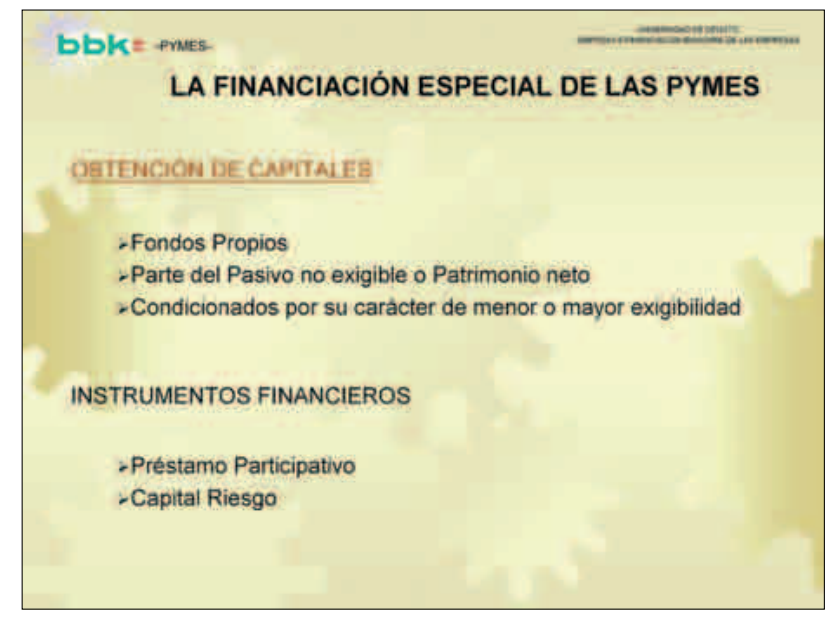

Figura 9

Se trata de recursos financieros que para la empresa van a tener la consideración de Fondos Propios, conformando parte del Pasivo no exigible o Patrimonio neto. Además, están condicionados por su carácter de menor exigibilidad por parte de los Acreedores.

Habitualmente, este tipo de financiaciones se articulan a través de dos instrumentos básicos: El Préstamo Participativo y la figura de Capital Riesgo.

En cuanto al Préstamo Participativo (Figura 10), se trata de un préstamo ordinario cuyo destino habitual es el afianzamiento de la independencia de la PYME mejorando su competitividad, financiando inversiones nuevas y/o desarrollando procesos de internacionalización.

Incluso, en algunos casos, son utilizados para procesos de reestructuración financiera.

Son préstamos a largo plazo cuyas características diferenciales con los demás son las siguientes: En cuanto al tipo de interés, es variable, en función de los resultados de la empresa.

Otra característica específica es que, para poder realizar amortizaciones anticipadas será necesario incrementar, en la misma magnitud, los fondos propios. 


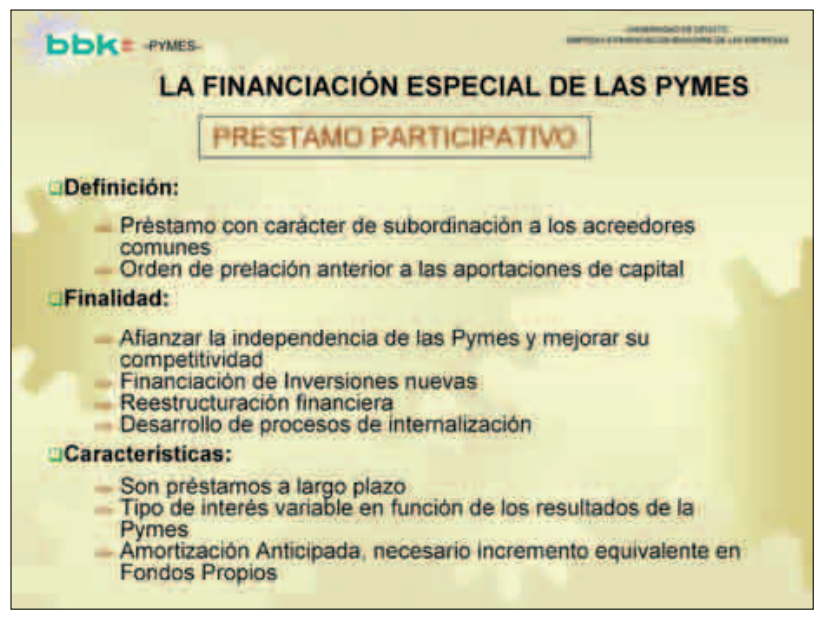

Figura 10

En cuanto a su exigibilidad, se trata de un préstamo subordinado a los acreedores comunes y su orden de prelación se sitúa inmediatamente antes de las aportaciones de capital.

Es una fórmula muy poco utilizada y son escasas las entidades que otorgan este tipo de financiación.

En nuestra Comunidad autónoma existe, por ejemplo, LUZARO E.F.C., S.A. (Figura 11), creada a iniciativa del Gobierno Vasco, en la que son sus principales socios el propio Gobierno Vasco, las Cajas Vascas y el Banco Guipuzcoano.

Ha otorgado créditos a 316 empresas por más de 100 millones de $€$.

En cuanto al capital riesgo (Figura 12), se caracteriza por ser una aportación de recursos que facilite el desarrollo de la empresa, prestándole además apoyo en la gestión, interviniendo y asesorando directamente a la misma.

Sus características vienen enmarcadas por la aportación de recursos estables (es una operación financiera de capital inversión), que se plasma en la toma de participación en una PYME, por parte de una sociedad especializada en esta función.

Este tipo de participaciones está gestionado por sociedades anónimas de capital riesgo o fondos de inversión de capital riesgo. 


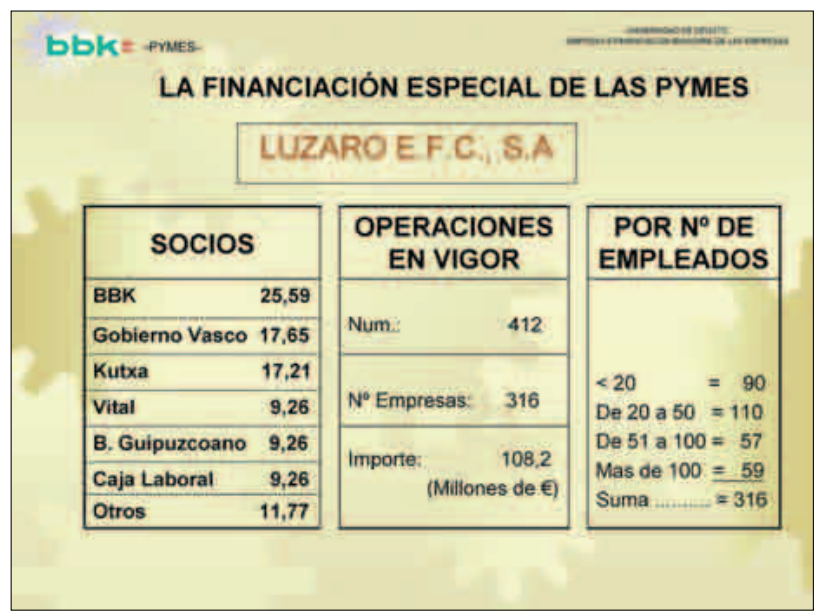

Figura 11

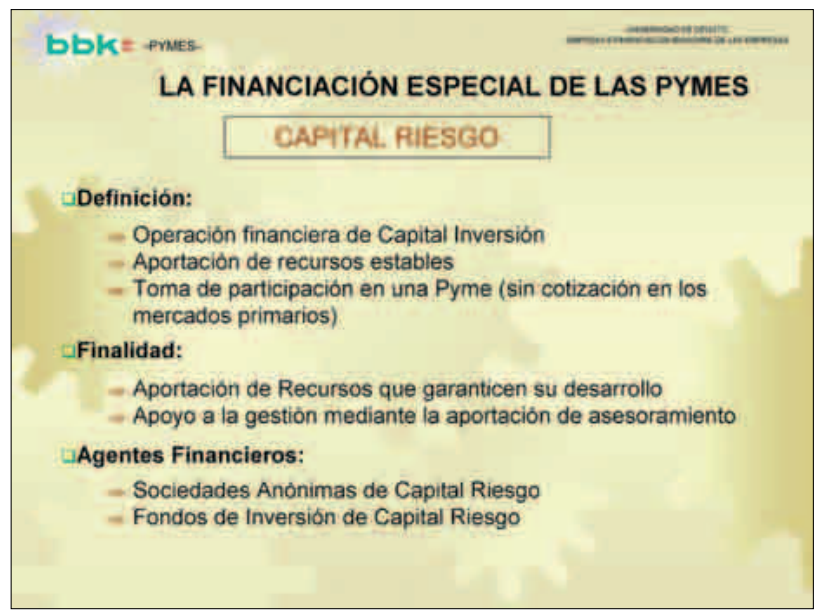

Figura 12

Las Sociedades de Capital Riesgo invierten en proyectos-empresas que, siendo atractivos para ellas, carecen de los recursos necesarios para dinamizarlos

Tratarán de obtener su beneficio a través de la plusvalía que pretendan alcanzar al vender su participación, una vez que la empresa ha 
sido potenciada y revalorizada. Las inversiones son temporales, no tienen vocación de permanencia.

Es una figura utilizada con más intensidad en otros países con economías más desarrolladas y que, en nuestro entorno, está creciendo paulatinamente.

Según la finalidad de la aportación, se pueden clasificar bajo las siguientes denominaciones (Figura 13).

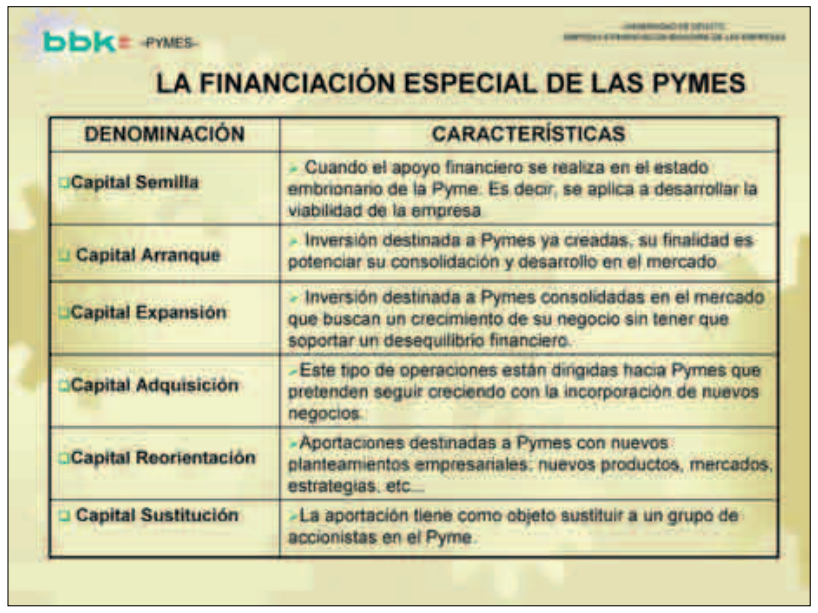

Figura 13

El Grupo de empresas TALDE es pionero en este tipo de actividades en Bizkaia (desde 1976) (Figura 14).

En la actualidad está compuesto por tres empresas:

-TALDE GESTION, Sociedad de Gestión de Entidades de Capital Riesgo S.A., que gestiona las otras dos sociedades:

-TALDE PROMOCION Y DESARROLLO, Sociedad de Capital Riesgo y TALDE CAPITAL, Fondo de Capital Riesgo.

La Sociedad de Capital Riesgo participa en 31 empresas por un valor neto contable de 28,1 millones de euros.

El Fondo de Capital Riesgo participa en 14 empresas por 13,1 millones de euros. 


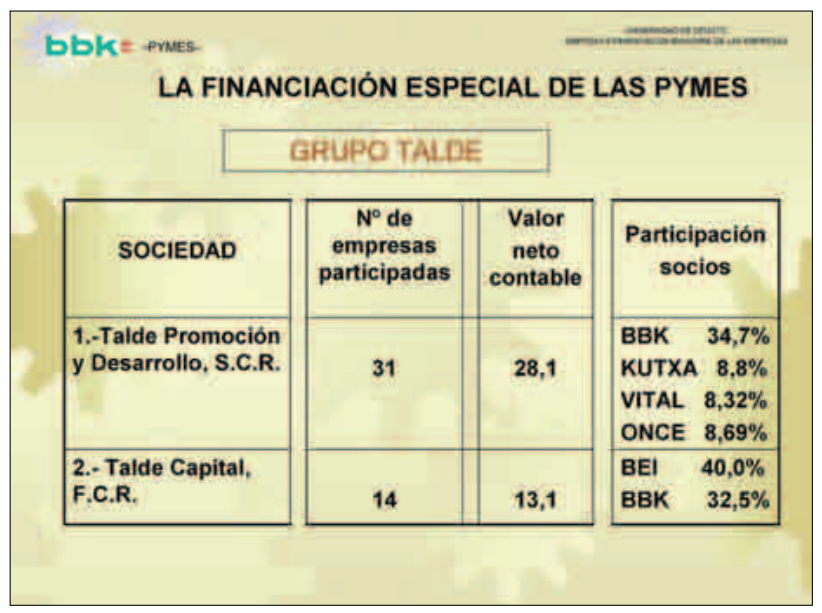

Figura 14

La segunda vía de financiación, la más importante en volumen, es la que se utiliza para la obtención de recursos para financiar los bienes soporte de la actividad económica de la empresa: EL INMOVILIZADO (Figura 15). Es decir, edificios, pabellones, maquinaria, etc...

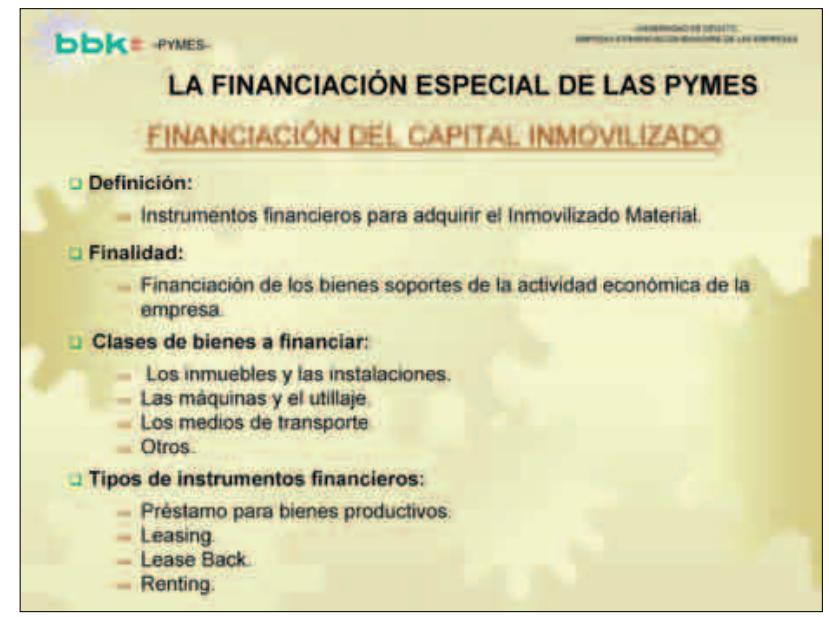

Figura 15 
Básicamente, se gestiona a través de Entidades Financieras con las que se negocia la obtención de Préstamos a un plazo (medio/largo) acorde al bien que se pretende financiar.

Existen distintos instrumentos financieros diseñados para mejor atender a cada necesidad en concreto. Los más utilizados son:

-El Préstamo para bienes productivos.

-El Leasing.

-El Lease Back.

-El Renting.

La primera de las figuras crediticias, el Préstamo (Figura 16), es la más habitual. En volumen de contratación, se estima que el $95 \%$ lo aglutinan los Préstamos y otro $4 \%$ el Leasing.

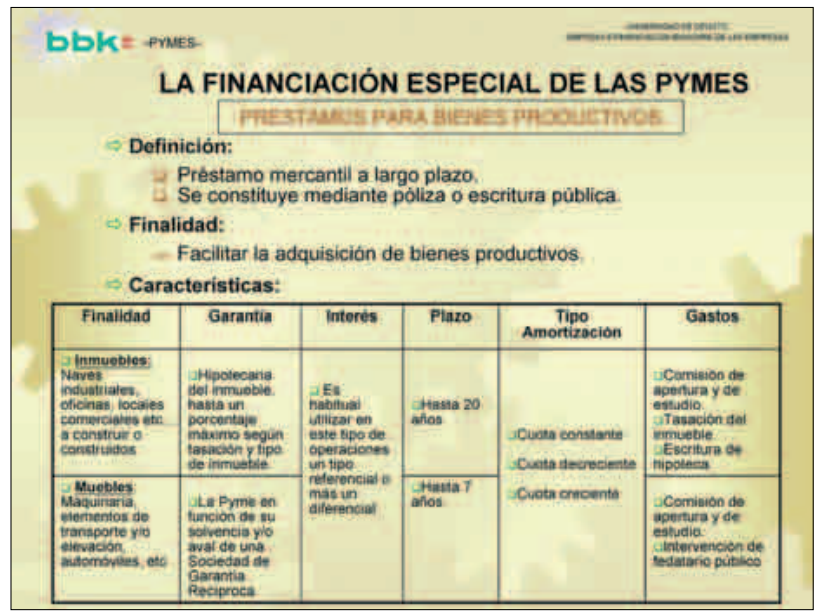

Figura 16

En función de la finalidad de la inversión y de la situación de la empresa, se establece un plazo de amortización, el cual, a su vez, incidirá en el tipo de garantías a aportar.

Es decir, cuanto más sólida sea la garantía (hipotecaria, etc...) más plazo se podrá obtener. No obstante, matizo que el plazo debe ser acorde con el Proyecto Empresarial en su conjunto y la duración del Bien a financiar. (Por ejemplo, sería incongruente financiar un vehículo con fondos obtenidos a un plazo superior al de su vida útil). 
Este tipo de operaciones, dado su extenso plazo y elevado importe se suelen contratar a tipo de interés variable, es decir, que con la periodicidad que se establezca (trimestral, semestral, anual, etc.) se revisa el interés a aplicar en función de un tipo de referencia (habitualmente, el Euribor al plazo elegido).

La amortización suele ser constante, pero también cabe adecuarse a otras modalidades (creciente, decreciente, etc ...).

Las garantías que se solicitan varían en función de las características de las operaciones:

Finalidad, Importe, Plazo, etc...

No obstante, es habitual contar con garantías adicionales a las de la propia Sociedad. Garantías hipotecarias de bienes inmuebles, garantía de socios, de otras sociedades e, incluso, el posible recurso a una sociedad de Garantía Recíproca.

Más adelante, me referiré a este tipo de sociedades.

Antes de avanzar más en el tema, permítanme un breve comentario sobre los parámetros que, bajo los criterios de gestión de riesgo de la Banca, enmarcan una estructura adecuada de una PYME (Figura 17).

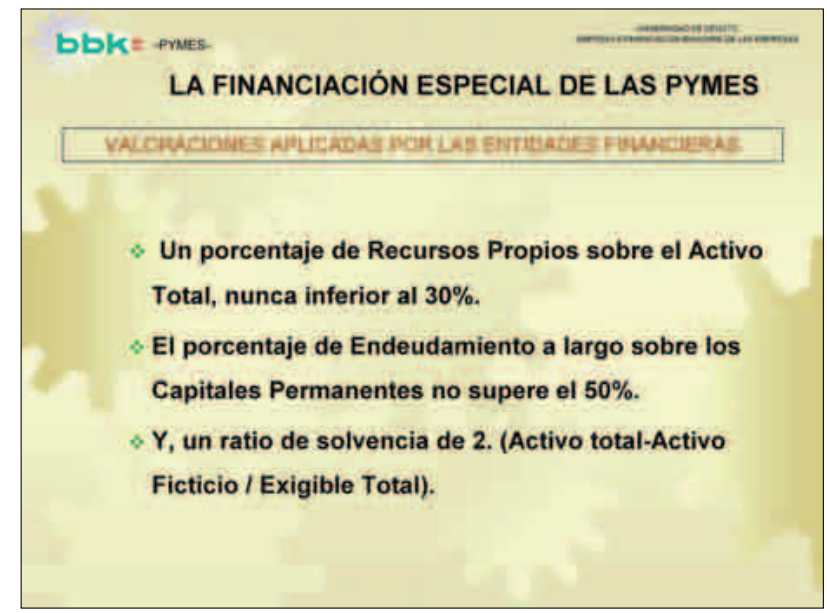

Figura 17 
Son tres ratios básicos cuyo cumplimiento avala, en principio, un adecuado equilibrio financiero.

Son los siguientes:

-El porcentaje de Recursos Propios sobre el Activo deberá alcanzar como mínimo, el 30 \%.

- En segundo lugar, el endeudamiento a largo no debe superar el $50 \%$ de los capitales permanentes.

-Finalmente, un ratio de solvencia de 2, es decir, que el Activo total menos el Activo ficticio duplique al Exigible total.

En el caso de no cumplirse alguno de ellos el tratamiento de las propuestas se verá abocado a un proceso más exigente y minucioso.

Siguiendo con los instrumentos para la financiación del Inmovilizado, veamos el Leasing y el Renting. En el Leasing (Figura 18) (arrendamiento financiero), el sistema de amortización es más flexible, aportando además ventajas fiscales sobre el préstamo tradicional (el doble de amortización para Inmuebles y el triple para bienes muebles). Por otra parte, no menos importante dado que se utiliza el propio bien como garantía básica de la operación, las garantías a exigir por la entidad financiera serán menores que en la financiación directa.

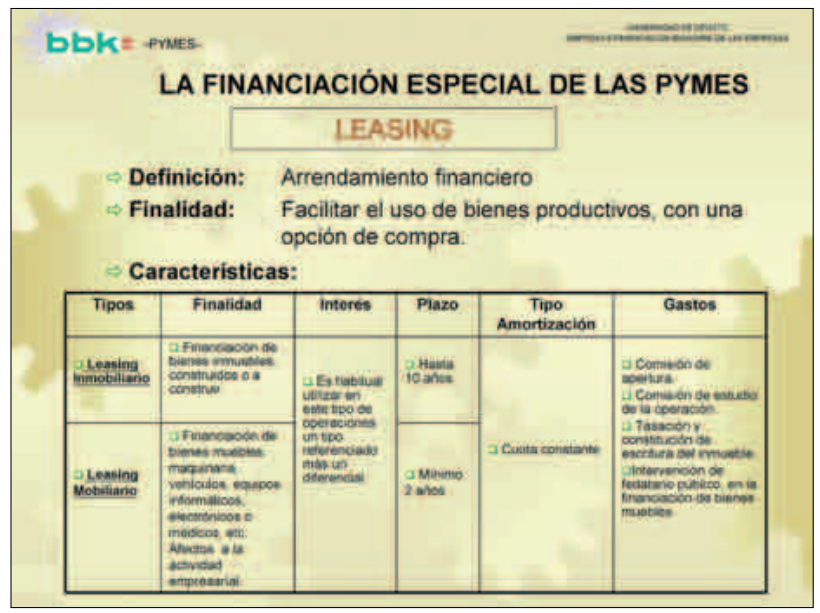

Figura 18 
Son operaciones a plazo mínimo de 2 años para el Leasing mobiliario y de 10 años en el caso del inmobiliario y, en cuanto al tipo de interés, normalmente va referenciado a tipo de interés variable.

Dentro del leasing existe la modalidad Lease-Back, en la que el propietario de un bien lo vende a una entidad de leasing para que, simultáneamente ésta se lo ceda para su uso inmediato mediante un contrato de arrendamiento financiero.

Su finalidad es la de obtener recursos financieros sin perder el uso del activo enajenado.

El lease-back se utiliza, principalmente, para transformar deuda a corto plazo en deuda a largo plazo, razón por la cual recibe el apelativo de «Leasing-Cosmético».

En este tipo de operaciones se engloban dos actos jurídicos:

- Una compra-venta.

- Un arrendamiento financiero.

En orden a este tipo de consideración el tratamiento fiscal no tiene las ventajas del Leasing tradicional.

En cuanto al Renting, se trata, asimismo, de un contrato de arrendamiento financiero que, además del uso del bien incorpora al mismo los gastos de mantenimiento durante el período de vigencia del contrato. En este caso, el arrendatario se despreocupa de todos los gastos de conservación y reparación puesto que van incluidos en la cuota mensual.

Las cuotas satisfechas se incorporan en su totalidad, excepto el IVA, como gastos ordinarios del ejercicio, con ligeras excepciones en algunos casos.

Dadas sus características, este producto financiero va dirigido, sobre todo, a bienes con un alto grado de obsolescencia técnica, permitiendo a la PYME mejorar su nivel de competitividad a través de la innovación sistemática de su equipamiento.

En el siguiente cuadro (Figura 19), se establecen a grandes rasgos las principales características de los distintos instrumentos que acabamos de analizar.

En función de la finalidad que se persiga se elegirá la figura que mejor se adapte a nuestras necesidades. 


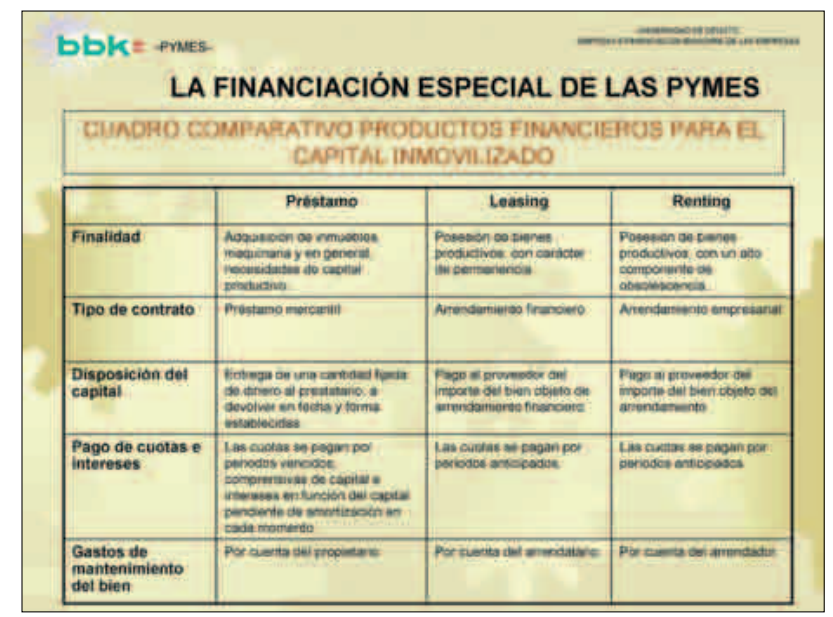

Figura 19

El segundo gran bloque de instrumentos financieros lo componen aquellos cuya finalidad es la de financiar el Circulante (Figura 20).

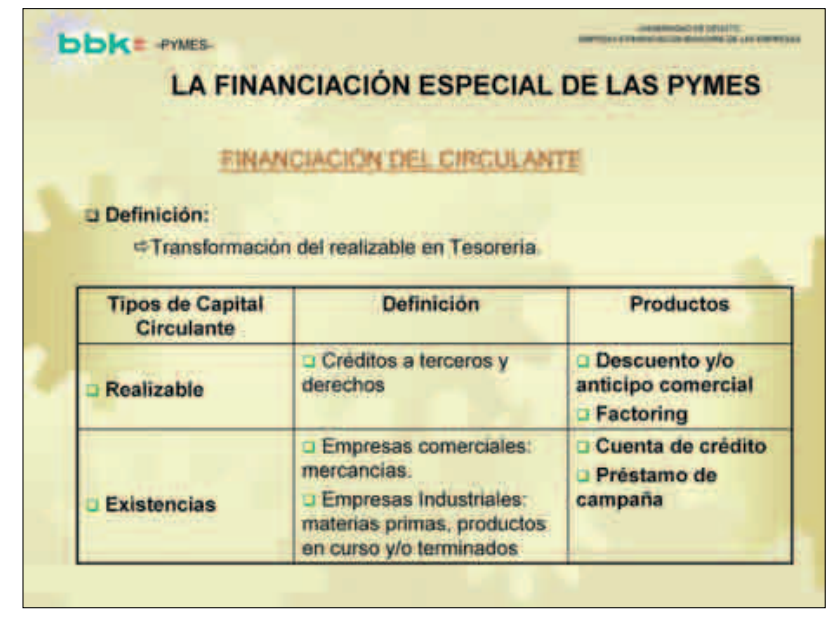

Figura 20

Se trata en esta ocasión de poder transformar tanto el realizable, como las existencias, en tesorería, aliviando así las necesidades financieras de las empresas. 
Los créditos y derechos que tengamos de terceros los podremos movilizar a través de instrumentos, como son:

- El Descuento y/o Anticipo Comercial.

- El Factoring.

Se entiende por Descuento Comercial (Figura 21), aquella línea de crédito a través de la que Títulos de Cambio como la Letra, el Pagaré, u otros que no tengan tal rango (por ejemplo, recibos), podrán ser aceptados dentro de la clasificación que una entidad financiera otorgue a la empresa.

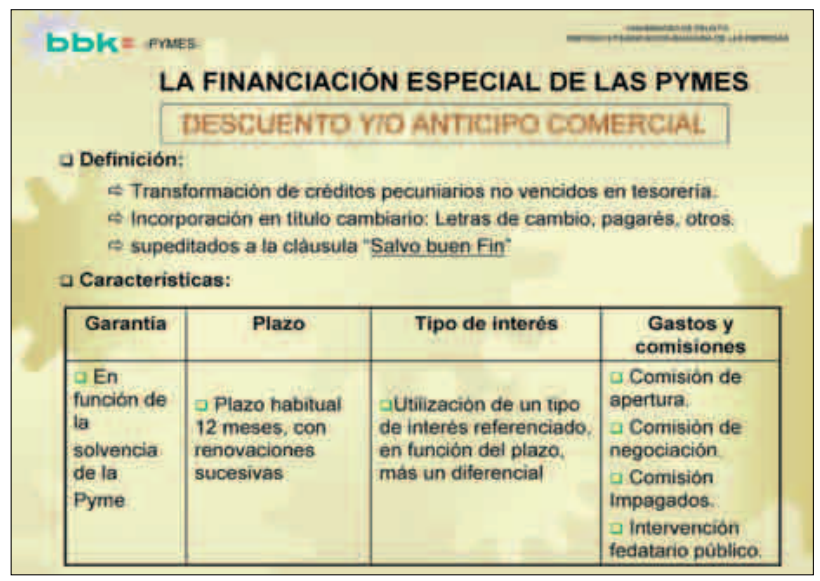

Figura 21

Estas Clasificaciones se otorgan, habitualmente, por un plazo de 12 meses, con un tipo de interés variable según el plazo del descuento, solicitándose garantías en función de cada PYME.

El Factoring (Figura 22) es, en esencia, una figura muy similar al Descuento Comercial.

La diferencia reside en que en este segundo caso, la empresa transfiere a la entidad financiera el crédito comercial que posee sobre su cliente, subrogándose dicha entidad financiera en todos los derechos del titular del crédito.

Según su modalidad, puede instrumentarse con o sin Recurso, no pudiendo ejercer la Entidad Financiera, en este último caso, ninguna acción contra la empresa cedente del Crédito. 


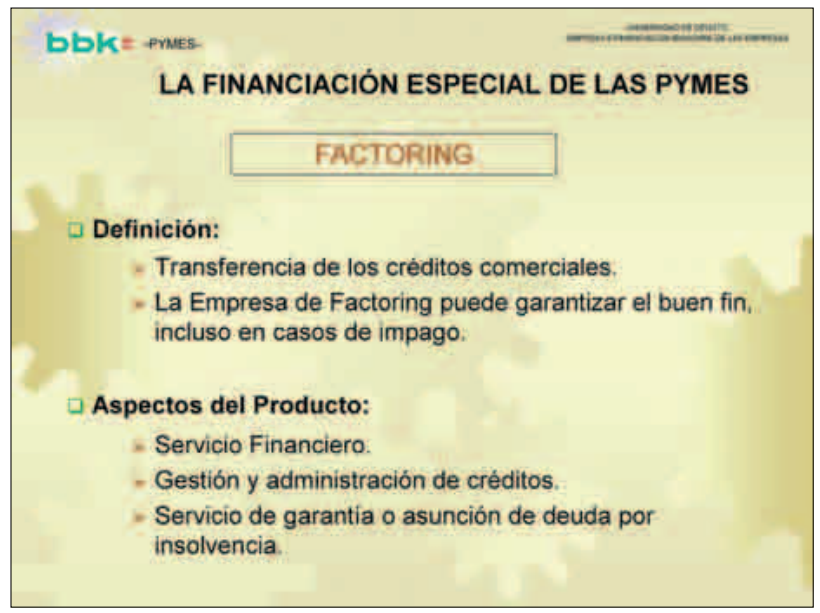

Figura 22

En consecuencia con el riesgo asumido, cuando se utiliza la forma SIN RECURSO la entidad financiera aplicará primas por riesgo de insolvencia, en función de la calidad del deudor, que encarecen sensiblemente la financiación.

El cuadro siguiente (Figura 23) recoge las diferencias entre ambos instrumentos.

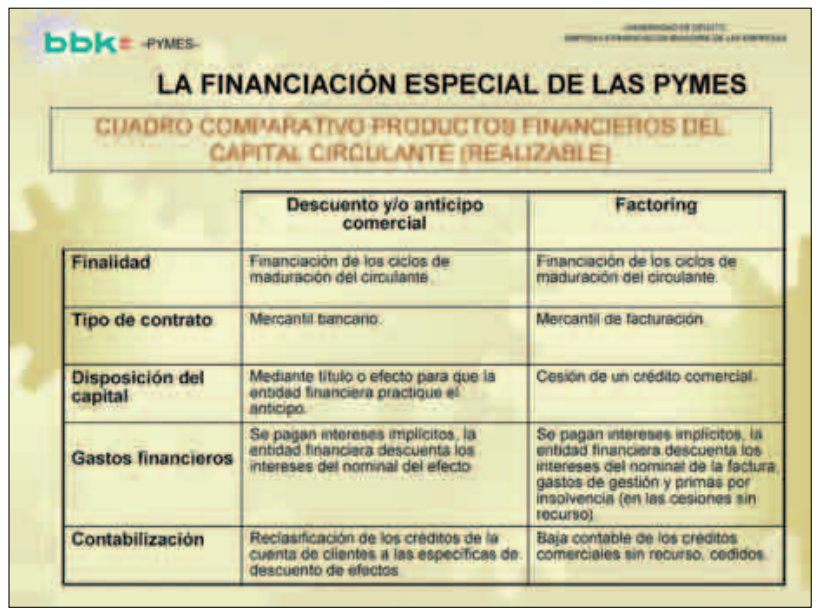

Figura 23 
Para la obtención de recursos que nos permitan operar sin tensión en los ciclos críticos, contamos con la Cuenta de Crédito y con el Préstamo de Campaña.

La Cuenta de Crédito (Figua 24), permite tener a disposición de la empresa los fondos necesarios para atender aquellos momentos agobiantes para la tesorería.

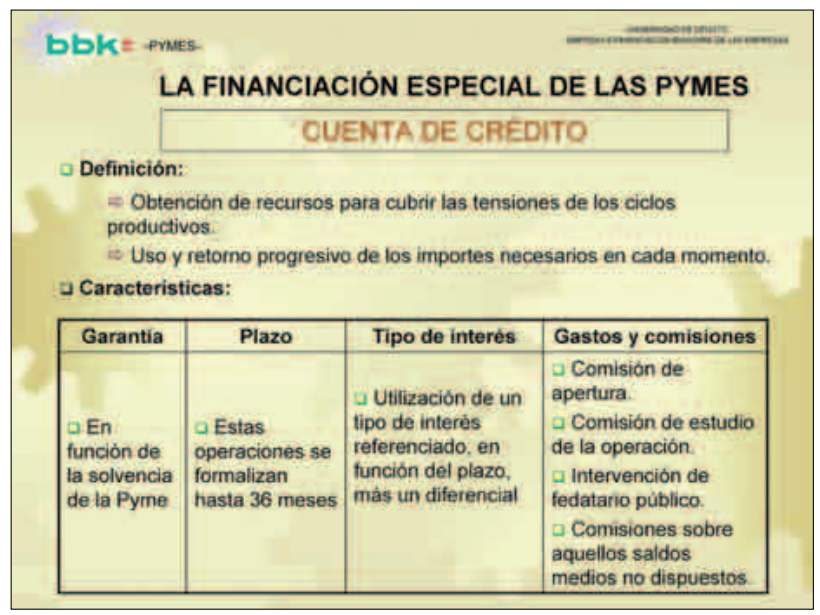

Figura 24

Esta capacidad financiera tiene además una virtud esencial, diferencial de todas las demás: su elasticidad. Es decir, permite obtener fondos y reponerlos con un funcionamiento idéntico al de una cuenta corriente.

En consecuencia, sólo se liquidarán intereses por los capitales dispuestos, permitiendo optimizar la gestión financiera de la Empresa.

Se suelen conceder a plazos cortos. Se utilizan tipos de interés variables y las garantías irán en función de la solvencia de la Sociedad.

Dado el bajo coste de estas operaciones, casi todas las empresas cuentan con este tipo de financiación, siempre útil en momentos de falta de liquidez.

Por último, el Préstamo de Campaña (Figura 25) es un instrumento adecuado para cubrir la necesidad de financiación derivada de la estacionalidad de la actividad empresarial. 


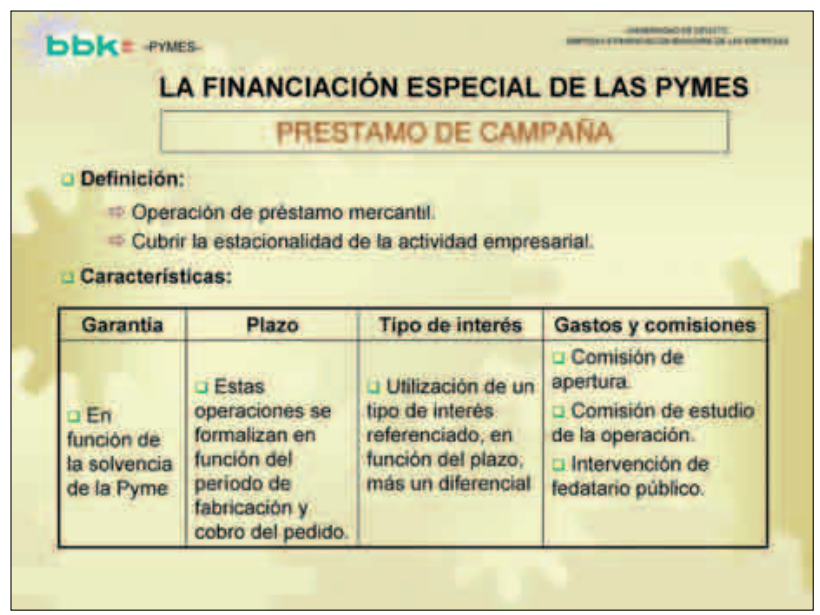

Figura 25

Se trata de un préstamo convencional en el que el plazo será aquel que corresponda en función del período de fabricación (compra de materias primas) y el del cobro del pedido.

Para terminar con el catálogo de los instrumentos financieros, dedicaremos un breve espacio a comentar la figura del CONFIRMING (Figura 26).

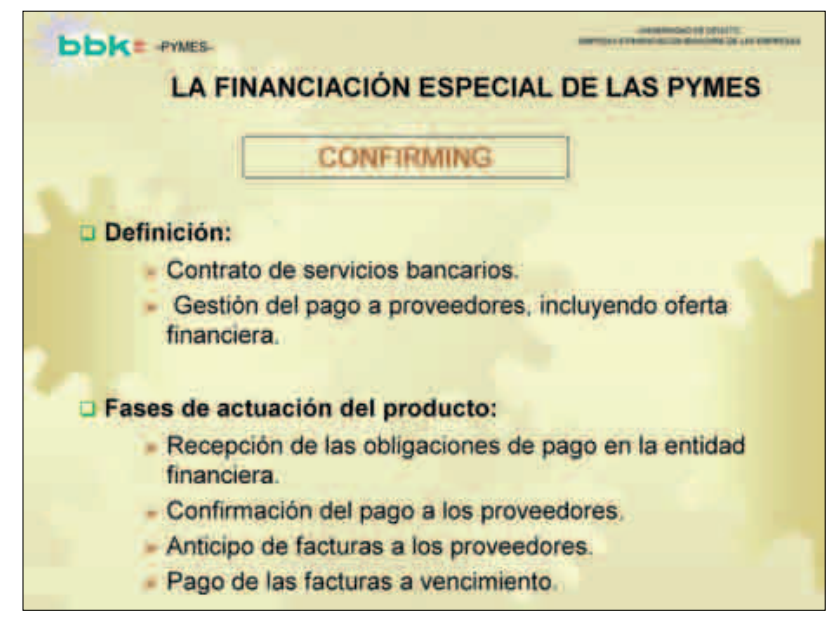

Figura 26 
Este es un servicio que se presta en general a Grandes Empresas con la finalidad de que éstas puedan facilitar a sus proveedores (Empresas PYMES) documentos que permitan a estas últimas acreditar la existencia de créditos a su favor $y$, en consecuencia, obtener financiación con la garantía de éstos.

Ventajas para los intervinientes:

- Para la empresa emisora, la facultad de poder organizar y calendar los pagos a sus Proveedores: La Gran Empresa Paga, no te cobran.

- Para la empresa receptora, la capacidad de obtener financiación con la garantía de la acreditación de la deuda emitida por su empresa cliente.

Es un servicio que se está implantando progresivamente en el escenario de la empresa de cierta dimensión.

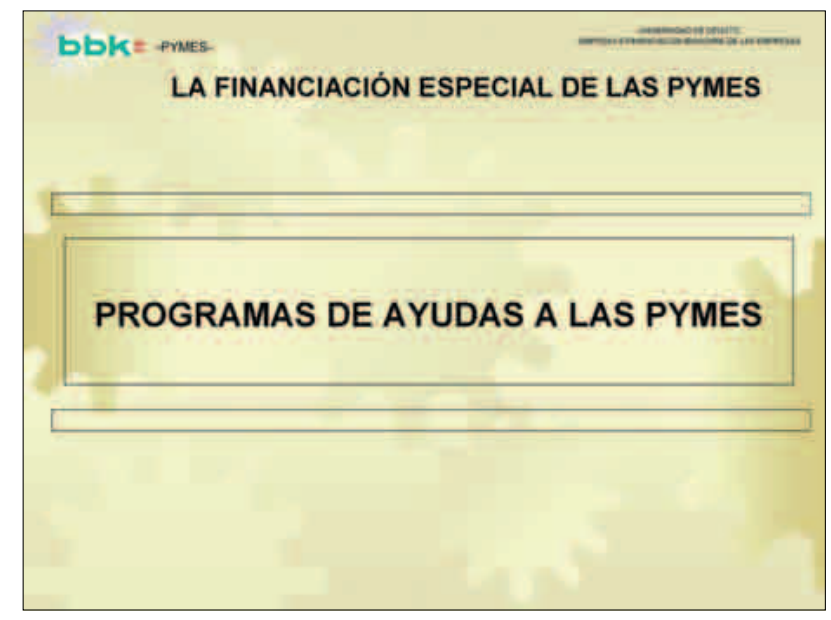

Examinados los diferentes instrumentos financieros, pasamos rápidamente a conocer los diferentes Programas y Ayudas con los que se pretende estimular y dinamizar, el importante segmento de las PEQUEÑAS Y MEDIANAS EMPRESAS.

Antes hemos descrito los Préstamos para Bienes productivos. Pues bien, es en esta figura donde se concentran la gran mayoría de ayudas para aliviar la carga financiera a las PYMES. 
Cuando las Administraciones establecen programas, convenios, etc... de ayudas, van prácticamente siempre asociados a proyectos de inversión de las Empresas en BIENES PRODUCTIVOS.

Se trata de «facilitar» al empresario la financiación de aquellos activos que le son necesarios para el arranque y/o mejora de su proyecto.

Enumerar en este momento las distintas ayudas existentes es imposible, dada su amplitud.

Por dar una idea de su extensión, baste decir que BBK colabora con la Confederación Empresarial de Bizkaia, «CEBEK» en la elaboración anual del Manual de Ayudas a las Empresas de Bizkaia. Se recogen y distribuyen a través de 3 diferentes soportes: Internet / CD o en un libro que cuenta con 398 páginas. Este Manual es un excelente trabajo que CEBEK y BBK ponen al servicio de las PYMES vizcaínas. En esta edición se recogen 196 ayudas a las que pueden acogerse las empresas.

La experiencia con que contamos para su elaboración (son ya 9 años colaborando), ha permitido ir mejorando esta herramienta de consulta, imprescindible para aquella PYME que pretenda abordar cualquier Proyecto de inversión.

Aunque las ayudas más demandadas siguen siendo las de «FlNANCIACION PREFERENTE PARA INVERSIONES», $26 \%$, registra un extraordinario aumento la solicitud de "APOYOS PARA LAS NUEVAS TECNOLOGIAS DE LA INFORMACION Y LAS COMUNICACIONES», que alcanza el $24 \%$.

Le siguen, por orden de importancia, «INNOVACION, GESTION Y TECNOLOGIA», con un $17 \%$, «Calidad» con un $11 \%$, etc.

El volumen de los recursos públicos vascos destinados a estas ayudas en el presente ejercicio, alcanza los 120 millones de euros para las empresas vizcaínas.

Destaca el aumento de las partidas dedicadas a la Innovación y a la Tecnología de la Información, en un $28 \%$, y retrocede en las Areas de Inversión y empleo, adaptándose en consecuencia, los apoyos institucionales a las nuevas necesidades de las empresas.

Son actores muy importantes en este apartado, empezando por el Gobierno Vasco, la Diputación Foral con planes a medida de las necesidades de nuestro entorno, la Comunidad Europea directamente y / o a través del. BEI, el Estado Español a través del ICO, etc. 
En cuanto a la aportación por instituciones, las vascas (Gobierno Vasco y Diputación Foral de Bizkaia) son las que mayor peso tienen, con un $71 \%$ sobre el total.

Con respecto a los destinatarios de las ayudas, las EMPRESAS INDUSTRIALES pueden acogerse a un $95 \%$ de las existentes, mientras que las EMPRESAS COMERCIALES y del SECTOR SERVICIOS tienen acceso a un $83 \%$, y el sector de LA CONSTRUCCION a un $80 \%$.

Destaca también el hecho de que las PYMES pueden acogerse a un $\mathbf{4 5} \%$ más de ayudas que las grandes empresas.

La casi totalidad de las Ayudas se concretan en subvenciones al tipo de interés de Préstamos, situándolo en niveles mínimos con arreglo a los precios de Mercado.

Los requisitos y características de las Ayudas son bastante similares, si bien, manteniendo su peculiaridad, de acuerdo con el fin para el que se crean.

A modo de ejemplo, voy a exponerles los criterios sustanciales en que se sustenta el PROGRAMA «AFI» de Ayudas Financieras a la Inversión, promovido por el Departamento de Industria, Comercio y Turismo del Gobierno Vasco, que, sin duda, es el más conocido y utilizado en nuestra Comunidad Autónoma (Figura 27).

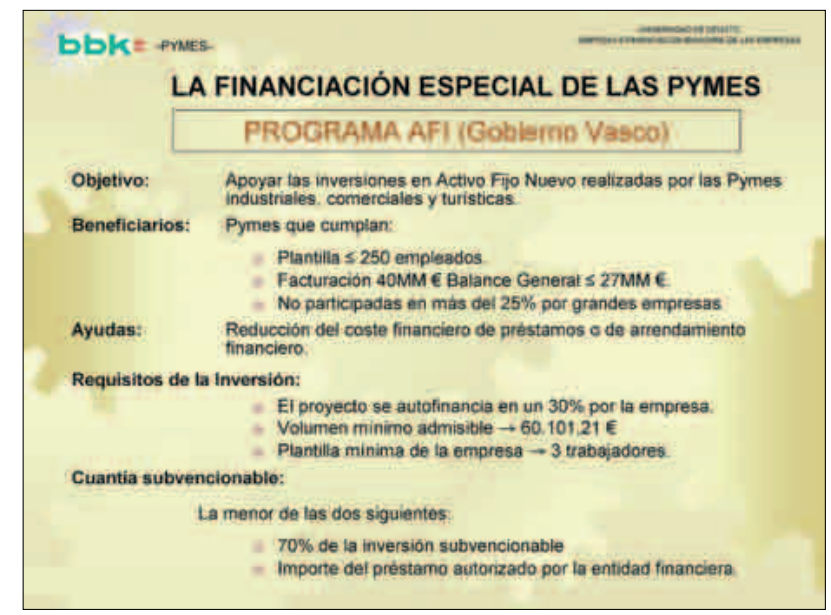

Figura 27 
Las ayudas de este programa van destinadas a las PYMES que vayan a invertir en ACTIVO FIJO NUEVO.

Se concretan en la reducción del coste financiero.

Se aceptan sólo proyectos que se autofinancien en, por lo menos un $30 \%$, y cuyo importe sea como mínimo de 60.101,21 euros.

Se especifican los tipos de interés máximos que pueden aplicar las entidades financieras $y$, finalmente, se detallan las Bonificaciones que se aplicarán a los tipos anteriores (Figura 28).

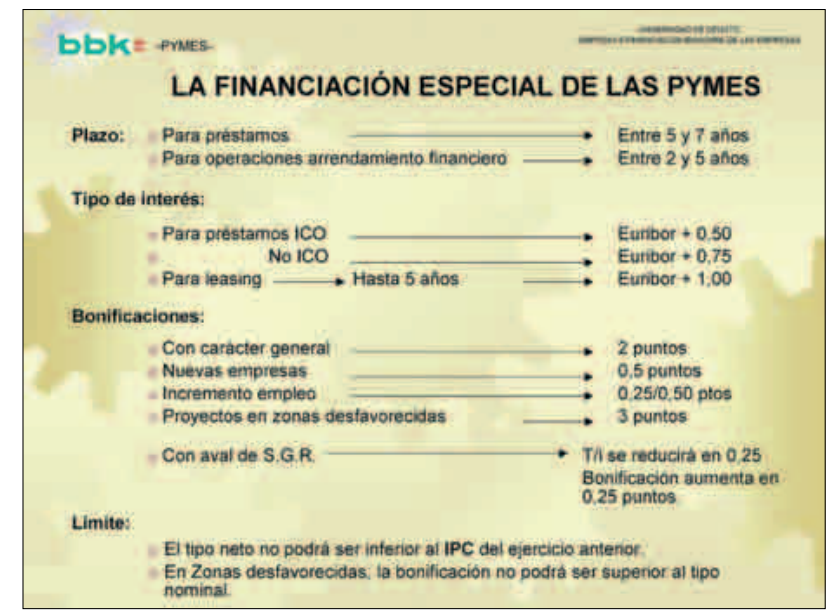

Figura 28

En general, estas ayudas van destinadas a potenciar el tejido industrial fomentando la creación y desarrollo de PYMES y MICROPYMES, como alternativa más coherente para la evolución de nuestra Economía.

La orientación de las ayudas va focalizada hacia las NECESIDADES más acuciantes de nuestra economía pendientes de resolver:

- Inversión para la creación y/o crecimiento de las PYMES.

- Creación de puestos de trabajo.

- Potenciación de la Investigación y el Desarrollo con mención especial para proyectos en nuevas tecnologías.

-Atención diferenciada al desarrollo de proyectos en Areas deprimidas.

-Etc ... etc. 
Durante toda la exposición han estado omnipresentes dos conceptos: solvencia y garantía, como condicionantes para la obtención de financiación por parte de las PYMES.

La dificultad de las Pequeñas y Medianas Empresas para poder aportar en ocasiones las garantías suficientes, ha motivado la implantación de un agente financiero que, con su actuación, amortigüe este efecto negativo: las Sociedades de Garantía Recíproca.

Promovidas por Administraciones Públicas y Asociaciones de interés general, tienen como objeto fundacional aportar a las PYMES garantía suficiente ante las Entidades de Crédito o los mercados de capital para poder así, obtener recursos que les permitan desarrollarse y ser competitivas.

Tienen la consideración de entidades financieras (están inscritas en el Registro del Banco de España, quien tiene asignado su control y supervisión).

Sus fondos provienen de las aportaciones de sus socios: Los Socios Protectores (Administraciones públicas, asociaciones de interés general, etc.) y los Socios Partícipes, aquellas PYMES que deseen beneficiarse de sus servicios mediante la suscripción de una cuota social.

El papel cada vez más importante que vienen desarrollando estas sociedades queda de manifiesto en los siguientes datos (Figura 29).

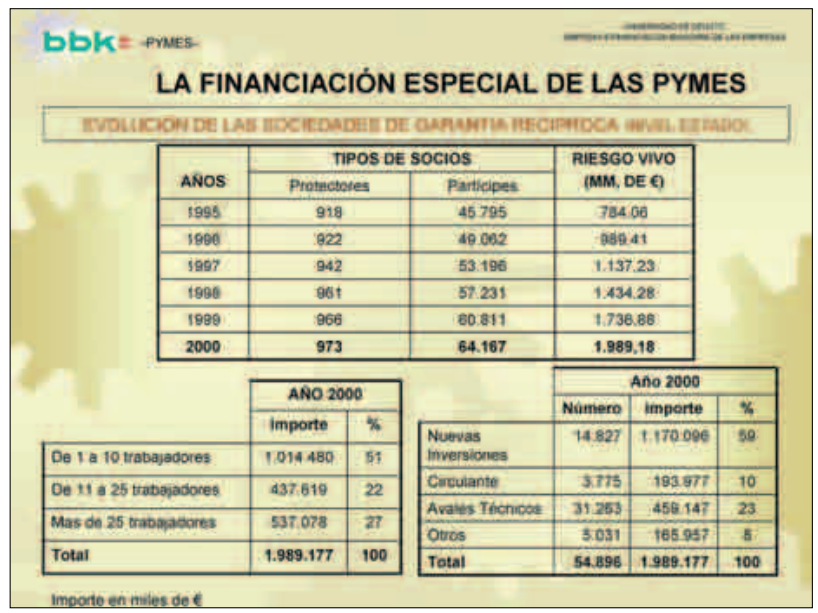

Figura 29 
Casi 2.000 millones de euros en operaciones avaladas a más de 64.000 PYMES.

Más de la mitad de ese esfuerzo ha ido dirigido a avalar operaciones de PYMES con menos de 10 trabajadores.

El $60 \%$ de los Recursos avalados se dedicaron a nuevas inversiones.

Estas sociedades tienen un papel muy importante también en el entorno europeo.

En el País Vasco, ELKARGI (Figura 30) desarrolla esta labor con una eficiencia que la convierte en una de las primeras Sociedades de Garantía Recíproca a nivel de todo el Estado.

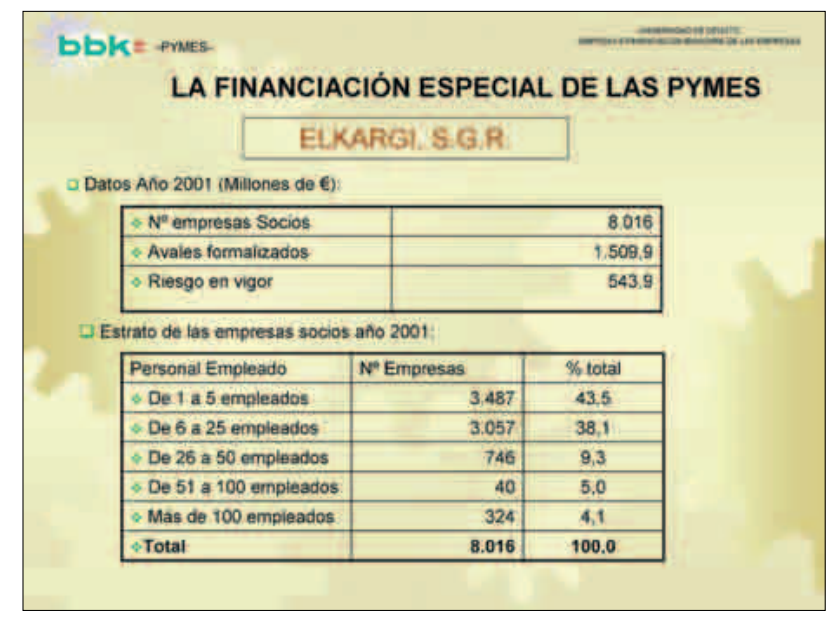

Figura 30

OIÑARRI, de más reciente creación, también va adquiriendo una posición relevante.

Para finalizar mi intervención, tengo que referirme al apoyo que BBK dedica a las PYMES en Bizkaia a través de dos ejes bien diferenciados.

El primero de ellos lo protagoniza la FUNDACION GAZTE LANBIDEAN (Figura 31) como el exponente de la voluntad de BBK en el apoyo a las empresas en la etapa seguramente más difícil: su nacimiento y desarrollo. 


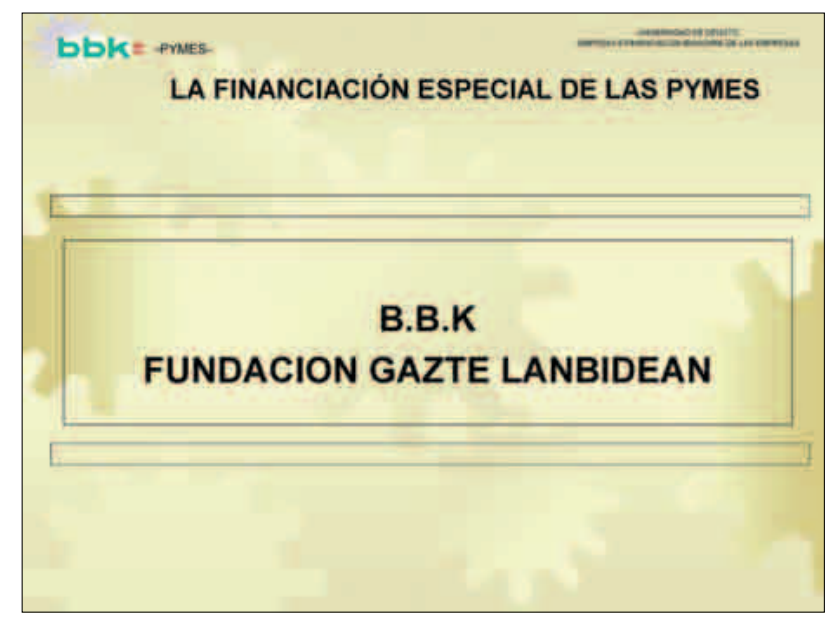

Figura 31

Ante la grave situación de paro y precariedad en el empleo, en 1998 «BBK» creó «GAZTE LANBIDEAN», con una dotación presupuestaria de 30 millones de Euros que, el año pasado, se vió ampliada en otros 12 millones.

En el área de auto-empleo y creación de empresas, la Fundación tiene por objetivo apoyar a los emprendedores-promotores en la puesta en marcha y seguimiento de proyectos empresariales.

Cuando se analizan los proyectos, GAZTE LANBIDEAN, a través de sus propios equipos, aplica el criterio de riesgo empresarial versus el de riesgo financiero comúnmente utilizado por las entidades financieras. De esta forma, ningún proyecto viable queda sin financiación por la falta de garantías (elemento crítico que analizábamos con anterioridad).

El apoyo de GAZTE LANBIDEAN tiene en cuenta, sobre todo, atender a los factores siguientes:

— La insuficiente capacidad de gestión de los emprendedores

- La endeble estructura financiera de los nuevos proyectos y

- La alta mortandad de las nuevas empresas.

Para atender a estas dificultades la Fundación colabora con los futuros empresarios en los procesos de: 
- Maduración de ideas

-Formación en la gestión empresarial

- Financiación en condiciones especiales

- Seguimiento, tutela y consultoría del proyecto durante sus 3 primeros años de vida e, incluso, co-gerencia en aquellos casos especiales que así lo requieran.

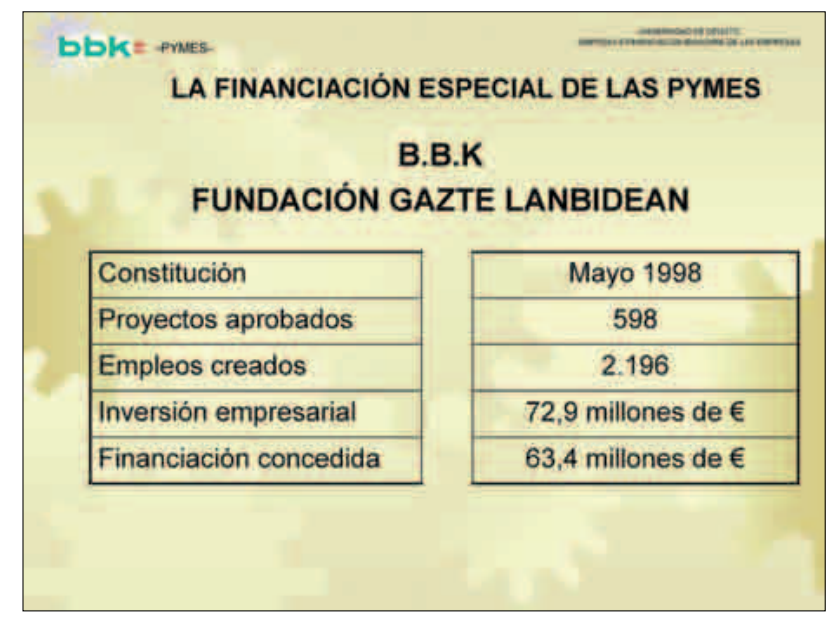

- 598 Proyectos/ Empresas aprobados/ puestos en marcha

- 2.196 empleos creados

- 72,9 millones de euros de inversión empresarial realizada y

- 63,4 millones de euros de financiación concedida por GAZTE LANBIDEAN

son los resultados alcanzados en estos cuatro años de actividad en esta difícil tarea.

Los múltiples esfuerzos desarrollados por el equipo de la Fundación con todos los interlocutores sensibles a esta problemática, y en la dinamización de los proyectos, se han visto compensados con la realidad que les acabo de describir.

Esta importante aportación tanto cuantitativa como cualitativamente, es el reflejo productivo de una parte del DIVIDENDO que BBK, como elemento diferenciador con otras Instituciones, retorna a nuestra sociedad. 
El segundo eje lo conforma la unidad financiera de atención especializada a las PYMES. A través de ella, BBK proporciona a las pequeñas y medianas empresas de Bizkaia un servicio CERCANO, a medida de sus necesidades.

Los más de 100 profesionales, distribuidos en las 20 Oficinas que se despliegan en nuestro territorio, suponen la mayor red financiera dedicada en exclusiva a las PYMES.

Esta vocación de BBK se ve compensada con los resultados alcanzados tras su corta existencia:

-1. a entidad en cuota de contacto con las PYMES de Bizkaia (más del $45 \%$ de las empresas tienen alguna relación con BBK).

-2. ${ }^{\text {a }}$ entidad en cuota de mercado,

-etc ... etc...

Esta es la realidad de la presencia de BBK en el sector.

Gracias por su atención. 